\title{
Erratum: Zhu et al. (2020). Application of the Kano Model and DEMATEL Technique to Explore Sustainable Promotion Strategies for Thai-Chinese Temples as Tourist Attractions. Religions 11: 199
}

\author{
Bo-Wei Zhu ${ }^{1}\left(\mathbb{D}\right.$, Zheng Huang ${ }^{2}$ and Lei Xiong ${ }^{3, *}$ \\ 1 Faculty of Humanities and Arts, Macau University of Science and Technology, Avenida Wai Long, Taipa, \\ Macau 999078, China; bwzhu@must.edu.mo \\ 2 Faculty of Decorative Arts, Silpakorn University, Ratchamankha Nai Rd., Nakhon Pathom 73000, Thailand; \\ 2003082@glut.edu.cn \\ 3 Academy of Fine Arts, South China Normal University, No. 55, Zhongshan Avenue, Tianhe District, \\ Guangzhou 510631, China \\ * Correspondence: kmt20005@gmail.com
}

check for

updates

Citation: Zhu, Bo-Wei, Zheng Huang, and Lei Xiong. 2021. Erratum: Zhu et al. (2020). Application of the Kano Model and DEMATEL Technique to Explore Sustainable Promotion Strategies for Thai-Chinese Temples as Tourist Attractions. Religions 11: 199. Religions 12: 793. https://doi.org/ $10.3390 /$ rel12100793

Received: 11 August 2021

Accepted: 18 September 2021

Published: 23 September 2021

Publisher's Note: MDPI stays neutral with regard to jurisdictional claims in published maps and institutional affiliations.

Copyright: (c) 2021 by the authors. Licensee MDPI, Basel, Switzerland. This article is an open access article distributed under the terms and conditions of the Creative Commons Attribution (CC BY) license (https:/ / creativecommons.org/licenses/by/ $4.0 /)$.
The authors would like to make the following corrections about the published paper (Zhu et al. 2020). The changes are as follows:

Update the first affiliation as "Faculty of Humanities and Arts, Macau University of Science and Technology, Avenida Wai Long, Taipa, Macau 999078, China", and remove the affiliation information of "School of Architecture and Environmental Arts, Sichuan Fine Arts Institute, Daxuecheng S Rd., Shapingba District, Chongqing 401331, China".

The authors and the Editorial Office would like to apologize for any inconvenience caused to readers by these changes. The change does not affect the scientific results. The manuscript will be updated and the original will remain online on the article webpage.

\section{Reference}

Zhu, Bo-Wei, Zheng Huang, and Lei Xiong. 2020. Application of the Kano Model and DEMATEL Technique to Explore Sustainable Promotion Strategies for Thai-Chinese Temples as Tourist Attractions. Religions 11: 199. [CrossRef] 